\title{
SPL Marketing Status Terminology
}

National Cancer Institute

\section{Source}

National Cancer Institute. SPL Marketing Status Terminology. NCI Thesaurus. Code C118778.

Terminology used to indicate whether a product is being marketed. 